\title{
Effects of highly active antiretroviral therapy (HAART) on platelet activating factor (PAF) metabolism in HIV-infected patients: in vivo results
}

\author{
AB Tsoupras*1, M Chini², N Tsogas², N Mangafas², G Stamatakis ${ }^{1}$, \\ $S$ Antonopoulou ${ }^{3}$, CA Demopoulos ${ }^{1}$ and MC Lazanas ${ }^{2}$
}

\begin{abstract}
Address: ${ }^{1}$ Faculty of Chemistry, University of Athens, Athens, Greece, ${ }^{23 r d}$ Internal Medicine Department - Infectious Diseases Unit, Red Cross General Hospital, Athens, Greece and ${ }^{3}$ Department of Science Nutrition-Dietetics, Harokopio University, Athens, Greece

* Corresponding author
\end{abstract}

\author{
from Ninth International Congress on Drug Therapy in HIV Infection \\ Glasgow, UK. 9-13 November 2008 \\ Published: 10 November 2008 \\ Journal of the International AIDS Society 2008, I I (SuppI I):PI05 doi:I0.II86/I758-2652-I I-SI-PI05
}

This abstract is available from: http://www.jiasociety.org/content/I I/SI/PI05

(c) 2008 Tsoupras et al; licensee BioMed Central Ltd.

\section{Purpose of the study}

PAF, a potent inflammatory mediator, seems to play a role in the pathogenesis of several AIDS manifestations. PAFantagonists have been studied in this context with promising results. We have previously described the in vitro interaction between HAART and PAF-induced platelet aggregation, as well as between HAART and the specific activities of the basic PAF metabolic enzymes.

\section{Methods}

In order to examine the in vivo interactions between PAF and HAART, we studied the effect of antiretroviral treatment on PAF-induced platelet aggregation and on the specific activities of the basic PAF metabolic enzymes from blood samples of HIV-patients.

\section{Summary of results}

15 naive, male HIV-infected patients were started on HAART. 8/15 received tenofovir-DF/emtricitabine/efavirenz (group A) and 7/15 abacavir/lamivudine/efavirenz (group B), based on our previous in vitro results showing the former having one of the most potent activities against PAF and the latter one of the weaker ones. The in vivo effects of HAART on the specific activities of the basic PAF metabolic enzymes (PAF-CPT, Lyso-PAF-AT and PAF-AH) of plasma, washed human leukocytes (WHLs), and washed human platelets (WHPs) at baseline and after 6 months on HAART were studied. 8/15 patients (four in each group), who completed 6 months on HAART were included in our final analysis. In group $\mathrm{A}$, a significant reduction (63\%) of the specific activity of PAF-CPT of WHLs was observed after 6 months while the specific activities of plasma-PAF-AH, Lyso-PAF-AT of WHLs, as well as both PAF-CPT and Lyso-PAF-AT of WHPs, remained relatively stable. In contrast, in group $\mathrm{B}$, PAFCPT of WHLs, plasma-PAF-AH, as well as both PAF-CPT and Lyso-PAF-AT of WHPs, remained relatively stable while the specific activity of Lyso-PAF-AT of WHLs was doubled.

\section{Conclusion}

Our preliminary in vivo results confirm the previous in vitro ones: group A's regimen retained its ability to reduce PAF production while group B's regimen seems to enhance it. Further studies are needed to confirm these results and to unveil any possible clinical implications of anti-PAF activity of HAART.

\section{Acknowledgements}

This work was supported by a grant from the Hellenic Society for the Research, Study and Education in Infectious Diseases.

\section{References}

I. Tsoupras B, et al.: Anti-platelet activating factor (PAF) effects of HAART: A new insight in the drug therapy of HIV infection. Intl Cong Drug Therapy in HIV Inf, Glasgow. Abstract P396. 1216 Nov 2006; 
2. Tsoupras B, et al:: Anti-platelet-activating factor effects of highly active antiretroviral therapy (HAART): A new insight in the drug therapy of HIV infection? Aids Res Human Retroviruses 2008 in press.

Publish with Bio Med Central and every scientist can read your work free of charge

"BioMed Central will be the most significant development for disseminating the results of biomedical research in our lifetime." Sir Paul Nurse, Cancer Research UK

Your research papers will be:

- available free of charge to the entire biomedical community

- peer reviewed and published immediately upon acceptance

- cited in PubMed and archived on PubMed Central

- yours - you keep the copyright

Submit your manuscript here:

http://www.biomedcentral.com/info/publishing_adv.asp 